\title{
Increased de novo Lipogenesis and Delayed Conversion of Large VLDL into Intermediate Density Lipoprotein Particles Contribute to Hyperlipidemia in Glycogen Storage Disease Type 1a
}

\author{
ROBERT H. J. BANDSMA, BERTHIL H. PRINSEN, MONIQUE DE SAIN VAN DER VELDEN, JAN-PETER RAKE, THEO BOER, \\ G. PETER A. SMIT, DIRK-JAN REIJNGOUD, AND FOLKERT KUIPERS

\begin{abstract}
Center for Liver, Digestive and Metabolic Diseases [R.H.J.B., T.B., D.J.R., F.K.], Department of Pediatrics [J.P.R., G.P.A.S.], University of Groningen, Groningen, 9700 RB, The Netherlands; Department of Metabolic and Endocrine Diseases [B.H.P., M.S.V.], University
\end{abstract} \\ Medical Center Utrecht, Utrecht, 3484 EA, The Netherlands
}

\begin{abstract}
Glycogen storage disease type 1a (GSD-1a) is a metabolic disorder characterized by fasting-induced hypoglycemia, hepatic steatosis, and hyperlipidemia. The mechanisms underlying the lipid abnormalities are largely unknown. To investigate these mechanisms seven GSD-1a patients and four healthy control subjects received an infusion of $\left[1-{ }^{13} \mathrm{C}\right]$ acetate to quantify cholesterogenesis and lipogenesis. In a subset of patients, $\left[1-{ }^{13} \mathrm{C}\right]$ valine was given to assess lipoprotein metabolism and $\left[2-{ }^{13} \mathrm{C}\right]$ glycerol to determine whole body lipolysis. Cholesterogenesis was $274 \pm 112 \mathrm{mg} / \mathrm{d}$ in controls and $641 \pm 201 \mathrm{mg} / \mathrm{d}$ in GSD-1a patients $(p<0.01)$. Plasma triglyceride-palmitate derived from de novo lipogenesis was $7.1 \pm$ 9.4 and $86.3 \pm 42.5 \mu \mathrm{mol} / \mathrm{h}$ in controls and patients, respectively $(p<0.01)$. Production of VLDL did not show a consistent difference between the groups, but conversion of VLDL into intermediate density lipoproteins was relatively retarded in all patients $(0.6 \pm 0.5$ pools/d) compared with controls $(4.3 \pm 1.8$ pools $/ \mathrm{d})$. Fractional catabolic rate of intermediate density lipoproteins was lower in patients $(0.8 \pm 0.6$ pools $/ \mathrm{d})$ compared with controls $(3.1 \pm 1.5$ pools/d). Whole body lipolysis was similar, i.e., $4.5 \pm 1.9 \mu \mathrm{mol} / \mathrm{kg} /$ min in patients and $3.8 \pm 1.9 \mu \mathrm{mol} / \mathrm{kg} / \mathrm{min}$ in controls. Hyperlipidemia in GSD-1a is associated with strongly increased lipid production and a slower relative conversion of VLDL to LDL. (Pediatr Res 63: 702-707, 2008)
\end{abstract}

$\mathrm{G}$ lycogen storage disease type 1a (GSD-1a, von Gierke Disease, OMIM\#232200) is caused by deficiency of glucose-6-phosphatase $\alpha$ (G6Pase- $\alpha$ ), which catalyzes the terminal steps in gluconeogenesis and glycogenolysis by converting glucose-6-phosphate to glucose and phosphate. G6Pase- $\alpha$ deficiency results in an inability to release glucose from liver, kidney, and possibly intestine. Phenotypical, G6Pase- $\alpha$ deficiency is characterized by growth retardation, hypoglycemia, hepatomegaly (massive hepatic steatosis) and lactic acidemia, as well as hypertriglyceridemia and hypercholesterolemia (1). Increased concentrations of cholesterol are found in both very LDL (VLDL) and LDL fractions

Received September 24, 2007; accepted January 4, 2008.

Correspondence: Folkert Kuipers, Ph.D., Center for Liver, Digestive and Metabolic Diseases, Room Y2.145, CMCV, University Medical Center Groningen, Hanzeplein 1, P.O. Box 30.001, 9700 RB Groningen, The Netherlands; e-mail: F.Kuipers@ med.umcg.nl

This work was supported by a grant from the Dutch Foundation for Scientific Research (NWO 920-03-123) and a grant from the Netherlands Diabetes Research Foundation (DFN 96.604). whereas HDL cholesterol and apolipoprotein A-I concentrations are usually decreased $(2,3)$. To control hypoglycemia in GSD-1a, patients often receive uncooked cornstarch which is accompanied by reductions in plasma lipid levels in GSD-1a $(4,5)$. The underlying mechanisms responsible for disturbed lipid metabolism in GSD-1a are largely unknown. We have previously reported increased rates of hepatic de novo lipogenesis and cholesterogenesis in two patients with GSD-1a (6), which may drive VLDL production by the liver. Lipogenesis and cholesterogenesis have both been implicated in regulation of VLDL secretion (7-9). In addition, insulin is known to suppress hepatic VLDL production (10): prevailing low insulin concentrations in GSD-1a patients may contribute to increased VLDL production in these subjects, but quantitative data are not available. Furthermore, defective lipoprotein lipolysis might also contribute to hypertriglyceridemia, because lipoprotein lipase activities have been reported to be low in GSD-1a (11). This may lead to delayed clearance of VLDLtriglycerides as was shown in a single patient with GSD-1a (12). To date, no reports simultaneously assessing lipid synthesis and lipoprotein kinetics in GSD-1a patients are available. Therefore, we addressed the question whether hyperlipidemia in GSD-1a is related to increased de novo lipogenesis/ cholesterogenesis leading to increased VLDL production or to a disturbance in lipolysis. Insight in the processes responsible for lipid abnormalities in GSD-1a may allow development of tailored therapies to reduce atherogenic lipid levels in these patients.

\section{METHODS}

Subjects and infusion protocol. Seven GSD-1a patients and four agematched healthy control subjects were studied. GSD-1a in patients was diagnosed by appropriate clinical tests (13) and confirmed by mutation analysis. Subject characteristics are summarized in Table 1. All GSD-1a patients were treated with allopurinol and an ACE inhibitor, which was continued during the study. None of the control subjects received any medication. Informed written consent from all subjects was obtained in accordance with the policy of the University Medical Center Groningen Ethical Committee. The study was approved by the institutional review board.

Abbreviations: CHREBP, carbohydrate-response element binding protein; G6Pase- $\boldsymbol{\alpha}$, glucose-6-phosphatase $\alpha$; GSD, glycogen storage disease; IDL, intermediate density lipoprotein; LXR, liver-X receptor; SREBP, sterol regulatory element-binding protein 
Table 1. Basic characteristics of GSD-1a patients and healthy control subjects

\begin{tabular}{|c|c|c|c|c|c|c|c|c|c|c|}
\hline & Sex & $\begin{array}{l}\text { Age } \\
(y)\end{array}$ & $\begin{array}{c}\text { BMI } \\
\left(\mathrm{kg} / \mathrm{m}^{2}\right)\end{array}$ & $\begin{array}{c}\text { Glucose } \\
(\mathrm{mM})\end{array}$ & $\begin{array}{l}\text { Lactate } \\
(\mathrm{mM})\end{array}$ & $\begin{array}{l}\text { Insulin } \\
(\mathrm{ng} / \mathrm{mL})\end{array}$ & ASAT & ALAT & Uric acid & Mutations \\
\hline \multicolumn{11}{|l|}{ Controls } \\
\hline 1 & $\mathrm{~F}$ & 23 & 27 & 5.5 & 1.4 & 19 & ND & ND & ND & \\
\hline 2 & $\mathrm{~F}$ & 23 & 28 & 5.4 & 1.5 & 40 & ND & ND & ND & \\
\hline 3 & M & 24 & 22 & 4.5 & 1.8 & 15 & ND & ND & ND & \\
\hline 4 & M & 22 & 23 & 4.9 & 1.0 & 11 & ND & ND & ND & \\
\hline Mean $\pm S D$ & & $23 \pm 1$ & $25 \pm 3$ & $5.1 \pm 0.4$ & $1.4 \pm 0.3$ & $21 \pm 13$ & & & & \\
\hline \multicolumn{11}{|l|}{ GSD-1a } \\
\hline 1 & M & 25 & 21 & 4.5 & 3.9 & 21 & 27 & 25 & 0.19 & G270V; Q347X \\
\hline 2 & $\mathrm{M}$ & 25 & 22 & 4.9 & 2.8 & 28 & 32 & 29 & 0.16 & G270V; Q347X \\
\hline 3 & $\mathrm{~F}$ & 13 & 25 & 4.2 & 2.9 & 33 & 59 & 59 & 0.10 & R170X; F327del \\
\hline 4 & $\mathrm{~F}$ & 17 & 24 & 4.2 & 0.7 & 11 & 67 & 28 & 0.17 & W63X; V338F \\
\hline 5 & M & 31 & 20 & 4.5 & 3.5 & 6 & 30 & 24 & 0.31 & Unknown \\
\hline 6 & $\mathrm{~F}$ & 22 & 27 & 4.6 & 2.3 & 7 & 29 & 27 & 0.38 & Unknown \\
\hline 7 & M & 21 & 20 & 4.0 & 5.0 & 7 & 62 & 96 & 0.33 & G266V; F327del \\
\hline Mean $\pm \mathrm{SD}$ & & $22 \pm 6$ & $23 \pm 3$ & $4.4 \pm 0.3$ & $3.0 \pm 1.3$ & $16 \pm 11$ & $44 \pm 18$ & $41 \pm 27$ & $0.23 \pm 0.10$ & \\
\hline
\end{tabular}

All concentrations represent mean value of multiple samples taken throughout experimental protocol.

All studies were performed in the metabolic ward of the University Medical Center Groningen. Subjects were admitted to the metabolic unit the evening before start of the isotope study. All subjects stopped consuming food or energy-containing drinks from 22:00 $\mathrm{h}$ onwards. At this time, a glucose infusion $(3.5 \mathrm{mg} / \mathrm{kg} / \mathrm{min})$ was started to maintain normoglycemia in the GSD-1a patients and to produce a semi-fasted steady state. Glucose was infused during the same period during the day and at an identical rate in control subjects and in patients. At $09.00(t=0)$, a $\left[1-{ }^{13} \mathrm{C}\right]$ acetate infusion $(0.20 \mathrm{mmol} / \mathrm{kg} / \mathrm{h}$ for $10 \mathrm{~h})$ was initiated in all subjects. In the control subjects and in a subset of patients $(n=4)$, a $\left[1-{ }^{13} \mathrm{C}\right]$ valine infusion $(15 \mu \mathrm{mol} / \mathrm{kg}$ priming dose $+15 \mu \mathrm{mol} / \mathrm{kg} / \mathrm{h}$ for $8 \mathrm{~h}$ ) was also started. At 17.00 , a $\left[2-{ }^{13} \mathrm{C}\right]$ glycerol infusion $(3.0 \mu \mathrm{mol} / \mathrm{kg}$ priming dose $+12.0 \mu \mathrm{mol} / \mathrm{kg} / \mathrm{h}$ for $2 \mathrm{~h})$ was initiated in the control subjects and a subset of patients $(n=3)$. Blood samples were taken hourly and after $t=8 \mathrm{~h}$ every $30 \mathrm{~min}$ in all subjects studied. Concentrations of glucose, lactate, and insulin were determined at $t=$ 0,5 and $8 \mathrm{~h}$ of the experimental protocol. Because these concentrations remained constant throughout the study, results were averaged. Indirect calorimetry was performed on two different occasions, between $t=1-3 \mathrm{~h}$ and between $t=5-7 \mathrm{~h}$

Biochemical analysis. Concentrations of cholesterol, cholesteryl ester, and triglycerides in plasma were determined using commercially available kits (Boehringer Mannheim, Germany). Fatty acid composition in VLDL fractions was analyzed by gas-chromatography as described earlier (14). Insulin concentrations were measured using a radio-immunoassay (Diagnostic Systems Laboratories, Webster, TX).

Stable isotope analysis. Cholesterol was extracted from total plasma and derivatized according to Neese et al. (15). VLDL1, VLDL2, intermediate density lipoproteins (IDL) and LDL fractions were isolated from plasma by ultracentrifugation according to de Sain-van der Velden et al. (16). Palmitate from VLDL fractions was methylated as described elsewhere (6). Cholesterol and fatty acids were analyzed by gas chromatography/mass spectrometry as described in detail earlier (17). Apolipoproteins from lipoproteins were precipitated using isopropanol (18), extracted as described previously (19) and subsequently hydrolyzed with $0.5 \mathrm{~mL}$ of $6 \mathrm{~N} \mathrm{HCl}$ for $24 \mathrm{~h}$ at $110^{\circ} \mathrm{C}$. Derivatization of the isolated amino acids from apoB100 to their corresponding $N(O)$-methoxycarbonyl methyl ester was done according to the method of Hušek (20). Analysis of isotopic enrichment of plasma $\left[{ }^{13} \mathrm{C}\right]$ valine was carried out by gas chromatography-mass spectroscopy on a Hewlett Packard 5890 Plus gas chromatograph coupled to a Finnigan SSQ 7000 quadruple mass spectrometer using methane positive-ion chemical ionization. The mass spectrometer was operated in the selected ion-monitoring mode at fragments with a mass-to-charge ratio (m/z) 190/191. Glycerol was isolated from plasma after precipitation of proteins with ice cold ethanol and derivatized to its tri-acetylated form, after addition of d5-glycerol as internal standard (21). Gas chromatography-mass spectroscopy analysis was performed, essentially as described by Ackermans et al. (21). The ions at m/z 159, 160, and 164, representing unlabeled, $\left[2-{ }^{13} \mathrm{C}\right]-$ and $\left[1,2,3-{ }^{2} \mathrm{H}_{5}\right]$-glycerol, were measured using selected ion recording.

Calculations. The fractions of newly synthesized cholesterol and palmitate molecules in plasma and VLDL, respectively, were quantified by mass isotopomer distribution analysis, as described in detail previously $(22,23)$. Absolute cholesterol synthesis rates were then calculated using a nonsteady state equation, applying an estimate of body free cholesterol pool size (15). Palmitate synthesis rates were calculated by multiplying plasma triglyceridepalmitate concentration with the fraction of newly synthesized palmitate at the end of the 10-h label infusion period. Lipoprotein kinetics were determined using SAAM II modeling (16). The model used was described earlier (24) and is shown in Figure 1. Plasma glycerol turnover was used as an indicator of whole body lipolysis and was calculated according to Ackermans et al. (21). Basically, the formula $R_{\mathrm{a}}=F / E_{\mathrm{p}}$ was used, where $F$ is the tracer infusion rate and $E_{\mathrm{p}}$ is the isotopic enrichment at steady state. Furthermore, a correction was made for the overlap in mass spectra caused by the introduction of the two stable isotopes.

Statistical analysis. All values reported are mean \pm SD. Significance was determined using the nonparametric Mann-Whitney $U$ test. Furthermore, bivariate correlation analyses were performed and tested using Spearman's rank correlation. Differences were considered significant at $p<0.05$.

\section{RESULTS}

Basal lipid parameters in controls and GSD-1a patients are shown in Figure 2. GSD-1a patients showed strongly elevated triglyceride concentrations and significantly higher concentrations of total cholesterol and apoB100. No significant differences in plasma HDL cholesterol, LDL-cholesterol and apoA-I concentrations between both groups were observed. FFA levels were

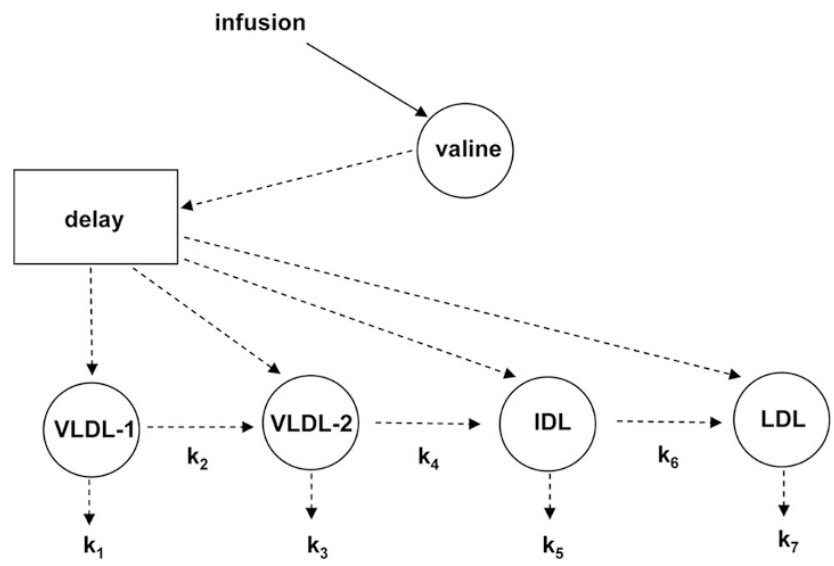

Figure 1. Multicompartmental model for apoB100 metabolism. The "valine" compartment represents plasma valine into which the tracer was injected. The "delay" compartment represents a delay compartment. Valine is incorporated in the lipoproteins via the other compartments. The k-values represent the rate constants. 
A
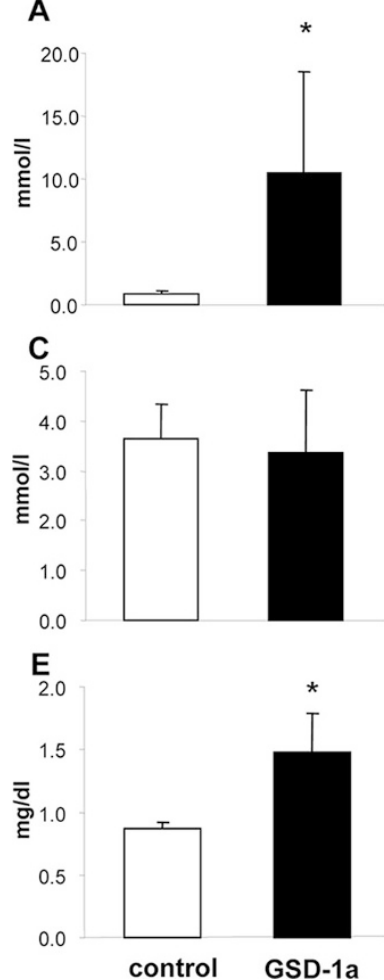

B
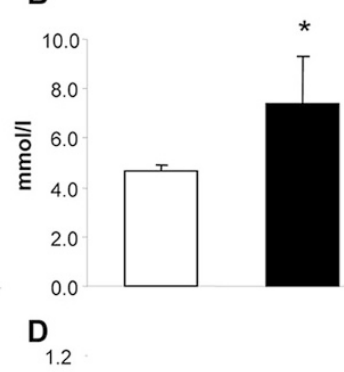

\section{$\mathbf{F}$}

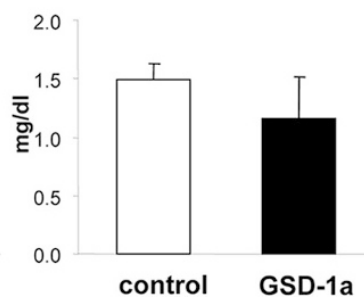

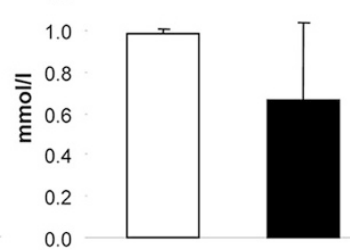

Figure 2. Plasma concentrations of triglyceride $(A)$, total cholesterol $(B)$, LDL-cholesterol $(C)$, HDL-cholesterol $(D)$, apoB $(E)$ and apoA-1 $(F)$ in GSD-1a patients $(n=7)$ and healthy control subjects $(n=4)$. Values are means $\pm \mathrm{SD}$. $* p<0.05$.

similar in both groups, i.e., $0.11 \pm 0.01 \mathrm{mM}$ in controls and $0.14 \pm 0.05 \mathrm{mM}$ in GSD-1a patients.

Hepatic de novo lipogenesis was strongly induced in patients as revealed by a strongly increased contribution of newly synthesized palmitate in VLDL $(86.3 \pm 42.5 \mu \mathrm{mol} / \mathrm{h})$ compared with controls $(7.1 \pm 9.4 \mu \mathrm{mol} / \mathrm{h})$, as depicted in Figure $3 A$. Cholesterol synthesis rates were three-fold increased in GSD-1a patients compared with control subjects (Fig. 3B). Increased cholesterogenesis and de novo lipogenesis were associated with lower enrichments of the acetyl-CoA precursor pool, calculated from cholesterol spectra (Fig. 3C), indicating an increased acetyl-CoA production (Fig. 3C). There was no significant difference between acetyl-CoA precursor pool enrichments calculated from cholesterol spectra and palmitate spectra.
Lipoprotein kinetic data in controls and GSD-1a patients are shown in Table 2. In one patient (no. 1), a thick solid layer containing triglycerides was formed in the VLDL fractions, preventing further accurate lipoprotein analysis. ApoB pool sizes were increased in the GSD-1a patients in the larger VLDL-1 and smaller VLDL-2 fractions. There seemed to be a large variability in VLDL metabolism in the GSD-1a patients and in controls. In two patients (nos. 2 and 7), GSD-1a was associated with a relatively low absolute synthesis rate of VLDL-1 and VLDL-2, but a much higher synthesis rate in another patient (no. 6). This last patient also showed a fractional catabolic rate of VLDL-1 (k1 $+\mathrm{k} 2$ in Fig. 1) and VLDL-2 $(\mathrm{k} 3+\mathrm{k} 4)$ that was higher than in the other two patients and more comparable with the controls. The transfer of VLDL-2 into IDL $(\mathrm{k} 4)$ was lower in all patients $(0.6 \pm 0.5$ pools/d) compared with controls $(4.3 \pm 1.8$ pools $/ \mathrm{d})$. The fractional catabolic rate of IDL $(\mathrm{k} 5+\mathrm{k} 6)$ was lower in all patients than in the control subjects. No clear differences in LDL metabolism were found between patients and controls. VLDL-1 particles were significantly larger in diameter in the GSD-1a patients compared with the control subjects, i.e., $86.7 \pm 9.2 \mathrm{~nm}$ and $57.3 \pm 7.7 \mathrm{~nm}$, respectively $(p<0.01)$.

Rates of appearance of glycerol were $3.8 \pm 1.9 \mu \mathrm{mol} / \mathrm{kg} /$ min in controls and $4.5 \pm 1.9 \mu \mathrm{mol} / \mathrm{kg} / \mathrm{min}$ in GSD-1a patients, indicating similar whole body lipolysis rates, at least in the semi-fasted state used in this study. Metabolic clearance of glycerol was lower in all three GSD patients $(0.06 \pm 0.01$ $\mathrm{L} / \mathrm{min} / \mathrm{kg})$ compared with controls $(0.10 \pm 0.03 \mathrm{~L} / \mathrm{min} / \mathrm{kg})$. Furthermore, values for respiratory quotients were similar in both groups under these conditions, i.e., $0.81 \pm 0.08$ in controls and $0.84 \pm 0.07$ in GSD-1a patients, indicating undisturbed whole body fat-oxidation in the GSD-1a patients.

\section{DISCUSSION}

GSD-1a is an inborn error of metabolism, the phenotypical characteristics of which underscore the important (patho)physiologic interactions that exist between carbohydrate and lipid metabolism. To the best of our knowledge, this is the first study to address lipoprotein kinetics, lipogenesis/cholesterogenesis and whole body lipolysis simultaneously in GSD-1a patients. Control subjects with high BMI were selected to match the GSD-1a patients some of whom also showed relatively high BMI values. A great variability existed between the patients with respect to the
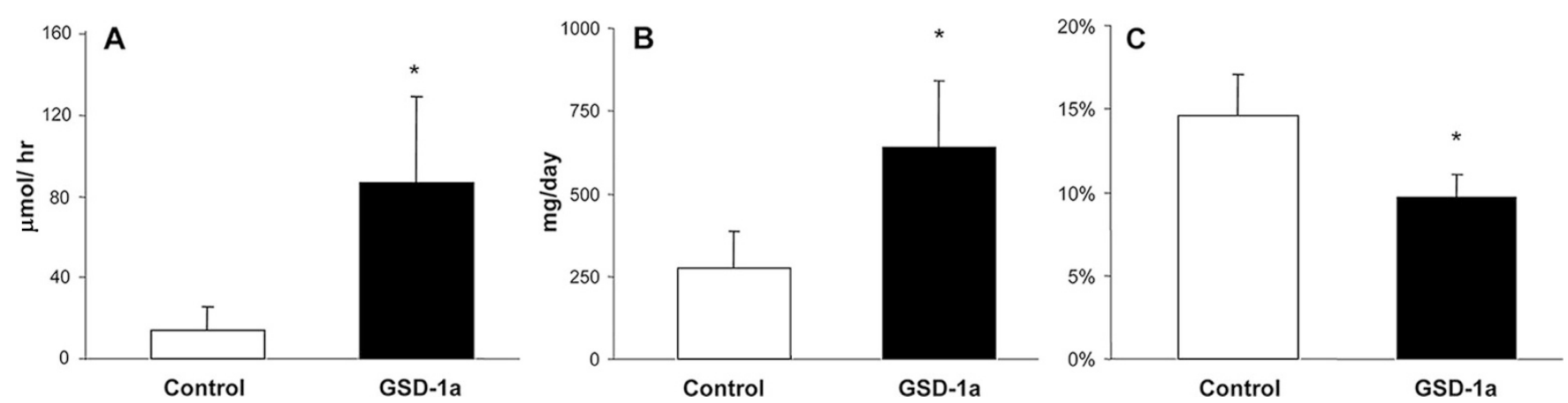

Figure 3. Total newly synthesized triglyceride-palmitate $(A)$ Cholesterol synthesis rates $(B)$ and acetyl-CoA pool enrichments $(C)$ in control subjects and GSD-1a patients. ${ }^{*} p<0.05$. 
Table 2. Lipoprotein metabolism in control subjects and GSD-1a patients

\begin{tabular}{|c|c|c|c|c|c|c|c|}
\hline & \multicolumn{4}{|c|}{ Controls } & \multicolumn{3}{|c|}{ GSD-1a } \\
\hline & 1 & 2 & 3 & 4 & 2 & 6 & 7 \\
\hline \multicolumn{8}{|l|}{ VLDL-1 } \\
\hline Pool size (mg) & 68 & 27 & 45 & 83 & 357 & 150 & 170 \\
\hline Synthesis rate $(\mathrm{mg} / \mathrm{kg} / \mathrm{d})$ & 3.2 & 0.8 & 2.1 & 6.7 & 1.2 & 17.4 & 1.8 \\
\hline Transfer (pools/d) & 3.1 & 2.3 & 3.8 & 4.2 & 0.1 & 5.2 & 0.6 \\
\hline Direct catabolism (pools/d) & 0.7 & 0 & 0 & 2.9 & 0.2 & 2.9 & 0 \\
\hline Total FCR (pools/d) & 3.8 & 2.3 & 3.8 & 7.1 & 0.2 & 8.1 & 0.6 \\
\hline \multicolumn{8}{|l|}{ VLDL-2 } \\
\hline Pool size (mg) & 156 & 116 & 85 & 78 & 187 & 362 & 277 \\
\hline Synthesis rate $(\mathrm{mg} / \mathrm{kg} / \mathrm{d})$ & 9.0 & 1.6 & 3.8 & 2.7 & 0.4 & 9.8 & 1.5 \\
\hline Transfer (pools/d) & 5.3 & 1.6 & 5.6 & 4.6 & 0.1 & 1.1 & 0.6 \\
\hline Direct catabolism (pools/d) & 0.7 & 0 & 0 & 2.9 & 0.2 & 2.9 & 0 \\
\hline Total FCR (pools/d) & 6.0 & 1.6 & 5.6 & 7.5 & 0.2 & 4.0 & 0.6 \\
\hline \multicolumn{8}{|l|}{ IDL } \\
\hline Pool size (mg) & 161 & 134 & 205 & 179 & 115 & 494 & 206 \\
\hline Synthesis rate $(\mathrm{mg} / \mathrm{kg} / \mathrm{d})$ & 0.0 & 0.3 & 1.4 & 1.7 & 0.1 & 3.4 & 0.6 \\
\hline Transfer (pools/d) & 3.9 & 1.6 & 2.0 & 0 & 0 & 1.3 & 1 \\
\hline Direct catabolism (pools/d) & 1.2 & 0 & 0.8 & 2.9 & 0.2 & 0 & 0 \\
\hline Total FCR (pools/d) & 5.1 & 1.6 & 2.9 & 2.9 & 0.2 & 1.3 & 1.0 \\
\hline \multicolumn{8}{|l|}{$\mathrm{LDL}$} \\
\hline Pool size (mg) & 1686 & 1830 & 1544 & 1248 & 472 & 2387 & 1380 \\
\hline Synthesis rate $(\mathrm{mg} / \mathrm{kg} / \mathrm{d})$ & 0.0 & 2.1 & 0.8 & 1.1 & 0.2 & 1.7 & 1.3 \\
\hline Total FCR (pools/d) & 0.4 & 0.2 & 0.3 & 0.1 & 0.0 & 0.3 & 0.2 \\
\hline
\end{tabular}

FCR indicates fractional catabolic rate.

severity of the hyperlipidemia, insulin concentrations and to a lesser extent also BMI. It is widely known that a high BMI is associated with insulin resistance, which, in turn, has been to shown to greatly affect lipid metabolism. In this study, no correlation could be found between BMI or insulin levels and the degree of hyperlipidemia (data not shown), indicating that the underlying metabolic disorder has a much greater effect on lipid metabolism in GSD-1a patients than obesity or insulin resistance.

De novo lipogenesis was strongly increased in the GSD-1a patients, compared with the healthy control subjects. Increased de novo lipogenesis was noted earlier by us in a case report (6) and in an animal model of GSD-1 (17). Hepatic de novo lipogenesis is under control of sterol regulatory elementbinding protein-1 (SREBP-1) $(25,26)$, Liver-X receptor (LXR) (27) and the carbohydrate-response element binding protein (CHREBP) $(28,29)$. SREBP1c, which is the subtype mostly responsible for activation of de novo lipogenesis, is under control of insulin. Insulin concentrations during the study were low in some GSD-1a patients and relatively high in other patients. A clear role of SREBP in the induction of de novo lipogenesis is therefore not likely in GSD-1a. LXR is activated by oxysterols, oxygenated derivatives of cholesterol. In GSD-1a with strongly increased plasma cholesterol concentrations, de novo lipogenesis stimulation through activation of LXR represents a possible pathway. Xylulose-5-phosphate is the activator of CHREBP, by stimulating its translocation to the nucleus and increasing its expression (30). Strongly increased hepatic glucose-6-phosphate levels in GSD-1a are expected to lead to an increased flux through the pentosephosphate cycle through which xylulose-5-phosphate is formed. De novo lipogenesis is therefore likely to be activated through induction of CHREBP in GSD-1a. Furthermore, GSD-1a was associated with a decrease in acetyl-CoA pre- cursor pool enrichments, indicating an increased flux through this pool. This increased flux, leading to increased production of acetyl-CoA, which is the precursor for cholesterogenesis and de novo lipogenesis, could possibly stimulate de novo lipogenesis directly, although no evidence is present to support this. However, in an acute animal model of GSD-1, cholesterol synthesis was not stimulated despite an increased production acetyl-CoA (17).

Increased cholesterol synthesis found in this study and an earlier case report (6) could very well be a major contributor to the hypercholesterolemia in GSD-1a. Cellular cholesterol synthesis is under control of SREBP-2, which becomes inactivated by increased intracellular sterol contents (31). However, we did not find an increase in cholesterol synthesis rates in an acute animal model of GSD-1 (17). This might indicate that increased cholesterol synthesis in GSD-1a patients might be caused by indirect mechanisms, although a role of SREBP-2 cannot be excluded. In the present study, no difference in LDL catabolism was observed in vivo in the patients. Older studies found increased LDL-cholesterol concentrations $(2,3)$ and Levy et al. (32) showed a decreased in vitro uptake of LDL particles by fibroblasts isolated from GSD-1 patients. It could be that these differences in LDL metabolism between studies are related to the degree of dietary control in GSD-1a patients.

Limited data exists with respect to lipoprotein kinetics in GSD-1. A case report in one GSD-1a patient noted similar VLDL production rates but strongly decreased VLDL clearance rates compared with control subjects (12). Indirect evidence suggestive of decreased VLDL clearance, related to decreased activity of lipoprotein lipase, has been reported previously $(2,11,33)$. In this study, low rates of VLDL particle production were found in two GSD-1a patients, but a very high rate in another patient. In an acute animal model of 
GSD-1, VLDL production was not altered (17), despite massive induction of lipogenesis and severe hepatic steatosis. These data indicate that other factors are responsible for determining VLDL production rates than metabolic consequences of G6Pase- $\alpha$ deficiency alone. It is generally assessed that hepatic fat content correlates with VLDL production (34) and that GSD-1a is associated with hepatic steatosis (35). In this study, the degree of hepatic steatosis was not determined and thus its effect on number or size of the VLDL produced could not be determined. One must take into account that the patients in whom we studied lipoprotein kinetics had less severe hypertriglyceridemia and lower insulin concentrations than the group as a whole. So, it cannot be ruled out that in patients with more severe hypertriglyceridemia and hyperinsulinemia, effects on lipoprotein kinetics might be more pronounced. Furthermore, patient (no. 6) with high production of VLDL, was also the patient with a much larger BMI, which could be related to a relative insulin resistance leading to less effective suppression of VLDL production by insulin in this patient. Finally, the variability in lipoprotein kinetics between the various patients could in theory be related to different patient compliance to the dietary treatment, although no clear indications for different treatment compliance were present. Conversion of VLDL-1 into VLDL-2 and onwards to LDL was relatively slow in the GSD-1a patients, although patient 6 showed a high conversion rate. The increased VLDL-apoB content is thus more likely to be related to decreased activity of lipoprotein lipase than to differences in VLDL production. In association with increased VLDL particle size, this could account for much of the observed hyperlipidemia. Lipogenesis induction by LXR leads to steatosis and formation of large VLDL particles, but not more particles (apoB) (36). Whether LXR plays a role in the development of steatosis and hypertriglyceridemia in GSD-1a remains to be determined.

Whole body lipolysis was similar in GSD-1a and control subjects, implicating that release of FFA and glycerol from adipose tissue is not altered in GSD-1a at least under "glucose clamped conditions." We therefore have no data to indicate that increased lipolysis, leading to more FFA delivery to the liver, contributes to the hyperlipidemia in GSD-1a patients. However, if some degree of insulin resistance is present in GSD-1a, this might be associated with increased activity of hormone sensitive lipase leading to increased lipolysis under postprandial conditions. The patients in whom we studied glycerol turnover had lower insulin concentrations than the other patients, which could lead to higher glycerol turnover rates in the patients we studied compared with the remaining patients. Finally, one must take into account that this study was performed under semi-fasted conditions, with relatively low insulin levels. Therefore, potential effects of insulin resistance could have remained unnoticed. Apart from an absence in differences in lipolysis, whole body fat oxidation was also not impaired, as indicated by similar RQ values. Of course, hepatic lipid oxidation might still be impaired as low ketone body concentration in plasma and severe hepatic steatosis are characteristic features in GSD-1a. Interestingly, metabolic clearance of glycerol was lower in all GSD-1a patients compared with the control subjects. Decreased glycerol clearance has been shown in alcoholic liver disease (37) and cirrhosis (38). Whether metabolic clearance of glycerol is related to the hepatic steatosis or general hepatic damage is not known.

The findings of these studies in combination with earlier studies could have implications for the treatment of the hyperlipidemia of GSD-1a patients. Fibrates have been shown, through activation of PPAR $\alpha$, to increase lipoprotein lipase activity (39) and hepatic $\beta$-oxidation. Case reports have indeed shown that fibrates decrease plasma triglyceride concentrations in GSD-1a patients $(12,40)$. Use of statins to lower cholesterol synthesis rates would likely have a strong effect on plasma cholesterol levels, although data supporting this hypothesis in GSD-1a patients is currently not available. Furthermore, use of statins has been shown to have strong effects on lipoprotein concentrations in multiple studies, mainly by lowering VLDL remnants through increased uptake by the LDL receptors (41). This study shows that GSD-1a is mainly associated with increased VLDL levels and statins could potentially substantially lower these levels. However, premature atherosclerosis has rarely been reported in GSD-1a patients, which suggests the existence of a protective mechanism in these patients. Potential benefits of lowering lipid concentrations in GSD-1a patients might therefore be limited. Treatments aimed at reducing hepatic steatosis might be of more clinical benefit, because it is associated with hepatic insulin resistance and development of fibrosis. Recent trials have addressed the use of thiazolinediones, which act as agonists of the nuclear hormone receptor peroxisome proliferator-activated receptor- $\gamma$, for the treatment of hepatic steatosis and have shown promising results (42). It would be worthwhile to study the effects of both statins and thiazolinediones in GSD-1a patients.

In conclusion, GSD-1a is associated with increased levels of de novo lipogenesis and cholesterogenesis, possibly contributing to the observed increased VLDL particle size without a clear effect on VLDL-apoB production rates. A relative defect in lipoprotein-triglyceride clearance might contribute to the strongly elevated hyperlipidemia in GSD-1a.

Acknowledgments. We thank Anke ter Harmsel and Theo van Dijk for excellent technical support.

\section{REFERENCES}

1. Smit GP, Rake JP, Akman HO, DiMauro S 2006 The glycogen storage diseases and related disorders. In: Fernandes J, Saudubray JM, van den Berghe G, Walter JH (eds) Inborn Metabolic Diseases: Diagnosis and Treatment. Springer, Wurzburg, Germany, pp 101-116

2. Levy E, Thibault LA, Roy CC, Bendayan M, Lepage G, Letarte J 1988 Circulating lipids and lipoproteins in glycogen storage disease type I with nocturnal intragastric feeding. J Lipid Res 29:215-226

3. Levy E, Letarte J, Lepage G, Thibault L, Roy CC 1987 Plasma and lipoprotein fatty acid composition in glycogen storage disease type I. Lipids 22:381-385

4. Chen YT, Bazzarre CH, Lee MM, Sidbury JB, Coleman RA 1993 Type I glycogen storage disease: nine years of management with cornstarch. Eur J Pediatr 152:S56S59

5. Fernandes J, Alaupovic P, Wit JM 1989 Gastric drip feeding in patients with glycogen storage disease type I: its effects on growth and plasma lipids and apolipoproteins. Pediatr Res 25:327-331

6. Bandsma RH, Rake JP, Visser G, Neese RA, Hellerstein MK, van Duyvenvoorde W, Princen HM, Stellaard F, Smit GP, Kuipers F 2002 Increased lipogenesis and resistance of lipoproteins to oxidative modification in two patients with glycogen storage disease type 1a. J Pediatr 140:256-260

7. Wang SL, Du EZ, Martin TD, Davis RA 1997 Coordinate regulation of lipogenesis, the assembly and secretion of apolipoprotein B-containing lipoproteins by sterol response element binding protein 1. J Biol Chem 272:19351-19358 
8. Watts GF, Naoumova R, Cummings MH, Umpleby AM 1995 Direct correlation between cholesterol synthesis and hepatic secretion of apolipoprotein B-100 in normolipidemic subjects. Metabolism 44:1052-1057

9. Riches FM, Watts GF, Naoumova RP, Kelly JM, Croft KD, Thompson GR 1997 Direct association between the hepatic secretion of very-low-density lipoprotein apolipoprotein B-100 and plasma mevalonic acid and lathosterol concentrations in man. Atherosclerosis 135:83-91

10. Lewis GF, Uffelman KD, Szeto LW, Steiner G 1993 Effects of acute hyperinsulinemia on VLDL triglyceride and VLDL apoB production in normal weight and obese individuals. Diabetes 42:833-842

11. Forget PP, Fernandes J, Haverkamp Begemann P 1974 Triglyceride clearing in glycogen storage disease. Pediatr Res 8:114-119

12. Wierzbicki AS, Watt GF, Lynas J, Winder AF, Wray R 2001 Very low-density lipoprotein apolipoprotein B-100 turnover in glycogen storage disease type Ia (von Gierke disease). J Inherit Metab Dis 24:527-534

13. Rake JP, Visser G, Labrune P, Leonard JV, Ullrich K, Smit GP 2002 Glycogen storage disease type I: diagnosis, management, clinical course and outcome. Results of the European Study on Glycogen Storage Disease Type I (ESGSD I). Eur J Pediatr 161:S20-S34

14. Hellerstein MK, Neese RA, Schwarz JM 1993 Model for measuring absolute rates of hepatic de novo lipogenesis and reesterification of free fatty acids. Am J Physiol 265:E814-E820

15. Neese RA, Faix D, Kletke C, Wu K, Wang AC, Shackleton CH, Hellerstein MK 1993 Measurement of endogenous synthesis of plasma cholesterol in rats and humans using MIDA. Am J Physiol 264:E136-E147

16. de Sain-van der Velden MG, Kaysen GA, Barrett HA, Stellaard F, Gadellaa MM, Voorbij HA, Reijngoud DJ, Rabelink TJ 1998 Increased VLDL in nephrotic patient results from a decreased catabolism while increased LDL results from increased synthesis. Kidney Int 53:994-1001

17. Bandsma RH, Wiegman CH, Herling AW, Burger HJ, ter Harmsel A, Meijer AJ, Romijn JA, Reijngoud DJ, Kuipers F 2001 Acute inhibition of glucose-6-phosphate translocator activity leads to increased de novo lipogenesis and development of hepatic steatosis without affecting VLDL production in rats. Diabetes 50:2591-2597

18. Egusa G, Brady DW, Grundy SM, Howard BV 1983 Isopropanol precipitation method for the determination of apolipoprotein B specific activity and plasma concentrations during metabolic studies of very low density lipoprotein and low density lipoprotein apolipoprotein B. J Lipid Res 24:1261-1267

19. de Sain-van der Velden MG, Rabelink TJ, Gadellaa MM, Elzinga H, Reijngoud DJ, Kuipers F, Stellaard F 1998 In vivo determination of very-low-density lipoproteinapolipoprotein B100 secretion rates in humans with a low dose of 1-[1-13C]valine and isotope ratio mass spectrometry. Anal Biochem 265:308-312

20. Hušek P 1991 Amino acid derivatization and analysis in five minutes. FEBS Lett 280:354-356

21. Ackermans MT, Ruiter AF, Endert E 1998 Determination of glycerol concentrations and glycerol isotopic enrichments in human plasma by gas chromatography/mass spectrometry. Anal Biochem 258:80-86

22. Faix D, Neese R, Kletke C, Wolden S, Cesar D, Coutlangus M, Shackleton CH, Hellerstein MK 1993 Quantification of menstrual and diurnal periodicities in rates of cholesterol and fat synthesis in humans. J Lipid Res 34:2063-2075

23. Neese RA, Benowitz NL, Hoh R, Faix D, LaBua A, Pun K, Hellerstein MK 1994 Metabolic interactions between surplus dietary energy intake and cigarette smoking or its cessation. Am J Physiol 267:E1023-E1034

24. Prinsen BH, Romijn JA, Bisschop PH, de Barse MM, Barrett PH, Ackermans M, Berger R, Rabelink TJ, de Sain-van der Velden MG 2003 Endogenous cholesterol synthesis is associated with VLDL-2 apoB-100 production in healthy humans. J Lipid Res 44:1341-1348

25. Shimano H, Yahagi N, Amemiya-Kudo M, Hasty AH, Osuga J, Tamura Y, Shionoiri F, Iizuka Y, Ohashi K, Harada K, Gotoda T, Ishibashi S, Yamada N 1999 Sterol regulatory element-binding protein-1 as a key transcription factor for nutritional induction of lipogenic enzyme genes. J Biol Chem 274:35832-35839

26. Shimomura I, Shimano H, Korn BS, Bashmakov Y, Horton JD 1998 Nuclear sterol regulatory element-binding proteins activate genes responsible for the entire program of unsaturated fatty acid biosynthesis in transgenic mouse liver. J Biol Chem 273:35299-35306

27. Tobin KA, Ulven SM, Schuster GU, Steineger HH, Andresen SM, Gustafsson JA, Nebb HI 2002 LXRs as insulin mediating factors in fatty acid and cholestero biosynthesis. J Biol Chem 277:10691-10697

28. Koo SH, Duverger N, Towle HC 2001 Glucose and insulin function through two distinct transcription factors to stimulate expression of lipogenic enzyme genes in liver. J Biol Chem 276:16033-16039

29. Towle HC, Kaytor EN, Shih HM 1997 Regulation of the expression of lipogenic enzyme genes by carbohydrate. Annu Rev Nutr 17:405-433

30. Kabashima T, Kawaguchi T, Wadzinski BE, Uyeda K 2003 Xylulose 5-phosphate mediates glucose-induced lipogenesis by xylulose 5-phosphate-activated protein phosphatase in rat liver. Proc Natl Acad Sci U S A 100:5107-5112

31. Sato R, Inoue J, Kawabe Y, Kodama T, Takano T, Maeda M 1996 Sterol-dependent transcriptional regulation of sterol regulatory element-binding protein-2. J Biol Chem 271:26461-26464

32. Levy E, Thibault L, Roy CC, Letarte J, Lambert M, Seidman EG 1990 Mechanisms of hypercholesterolaemia in glycogen storage disease type I: defective metabolism of low density lipoprotein in cultured skin fibroblasts. Eur J Clin Invest 20:253-260

33. Asayama K, Kato K, Anemiya S, Nozaki Y 1982 Postheparin plasma lipases in patients with hepatic glycogenosis. Horm Metab Res 14:555

34. Adiels M, Taskinen MR, Packard C, Caslake MJ, Soro-Paavonen A, Westerbacka J, Vehkavaara S, Hakkinen A, Olofsson SO, Yki-Jarvinen H, Boren J 2006 Overproduction of large VLDL particles is driven by increased liver fat content in man Diabetologia 49:755-765

35. McAdams AJ, Hug G, Bove KE 1974 Glycogen storage disease, types I to X: criteria for morphologic diagnosis. Hum Pathol 5:463-487

36. Grefhorst A, van Dijk TH, Hammer A, van der Sluijs FH, Havinga R, Havekes LM, Romijn JA, Groot PH, Reijngoud DJ, Kuipers F 2005 Differential effects of pharmacological liver $\mathrm{X}$ receptor activation on hepatic and peripheral insulin sensitivity in lean and ob/ob mice. Am J Physiol Endocrinol Metab 289:E829-E838

37. Johnston DG, Alberti KG, Wright R, Blain PG 1982 Glycerol clearance in alcoholic liver disease. Gut 23:257-264

38. Shangraw RE, Jahoor F 2000 Lipolysis and lipid oxidation in cirrhosis and after liver transplantation. Am J Physiol Gastrointest Liver Physiol 278:G967-G973

39. de Man FH, de Beer F, van der Laarse A, Jansen H, Leuven JA, Souverijn JH, Vroom TF, Schoormans SC, Fruchart JC, Havekes LM, Smelt AH 2000 The hypolipidemic action of bezafibrate therapy in hypertriglyceridemia is mediated by upregulation of lipoprotein lipase: no effects on VLDL substrate affinity to lipolysis or LDL receptor binding. Atherosclerosis 153:363-371

40. Greene HL, Swift LL, Knapp HR 1991 Hyperlipidemia and fatty acid composition in patients treated for type IA glycogen storage disease. J Pediatr 119:398-403

41. Vega GL, Grundy SM 1998 Effect of statins on metabolism of apo-B-containing lipoproteins in hypertriglyceridemic men. Am J Cardiol 81:36B-42B

42. Mendez-Sanchez N, Arrese M, Zamora-Valdes D, Uribe M 2007 Treating nonalcoholic fatty liver disease. Liver Int 27:1157-1165 